\title{
Does Platform Matter? A Case Study of Learning Management System
}

\author{
Gali Naveh and Amit Shelef
}

\begin{abstract}
In this research, the effect of the replacement of Learning Management System on students' satisfaction in a university and a college was examined. In the unique setting of the research, the only change made was of the platform, with no technological, pedagogical, organizational or other changes accompanying the process. A user satisfaction survey revealed that the platform change explains seven percents of the shift in students' satisfaction, and found no difference between the two institutes. Possible explanations and implications are suggested in the concluding section of the paper.
\end{abstract}

Index Terms-Information system success, learning management system, students satisfaction, technological platform.

\section{INTRODUCTION}

Learning management system (LMS) is an Information System (IS) designed to facilitate the interaction between an instructor and his or her students. LMSs are widely used in academia [1]. These systems support various teaching and learning activities such as posting learning material, sharing knowledge and resources, submitting and grading assignments and online assignments and exams. LMSs are used in various learning settings, from a fully virtual course to blended learning, i.e., as a supplement to a face-to-face course.

In this research, the success of LMS is measured in a unique situation of LMS platform change, with no other changes present in the technological, pedagogical and organizational surrounding. The success of the LMS is measured based on a widely used and validated measure students' satisfaction.

In the turn of the century, most academic institutes in Israel have implemented and widely used an LMS developed by Britannica Knowledge System (http://www.britannica-ks.com). Similarly to academic institutes all over the world, the adoption was wide and fast (e.g. [2]-[4]), although, the LMS mainly served as an administrative tool, for posting learning material and messages [5], [6]. A decade later, the use of web sites accompanying traditional teaching has become the mainstream, but maintenance of the LMS (i.e. upgrading, adding functionality, etc.) turned out to be cumbersome and expensive. As a result, universities and colleges in Israel looked for an alternative and migrated one by one to the open source LMS Moodle (https://moodle.org), which offers very similar functionality (i.e. posting learning and administrative

Manuscript received April 20, 2016; revised December 2, 2016.

Gali Naveh and Amit Shelef are with Shamoon College of Engineering, Beer Sheva, Israel (e-mail: GaliNaveh@sce.ac.il, amit.shelef@gmail.com). material, submission and grading of assignment, discussion forums, online exercises and exams, course calendar, etc., [7]). This research examines the impact of the switch between the two platforms on students' satisfaction in two academic institutes: Ben-Gurion University of the Negev and Shamoon College of Engineering.

Ben Gurion University (BGU) is a major center for teaching and research with over 17,000 students, studying for bachelor, master and doctorate degrees in over 40 departments, with approximately 900 of them studying in the department of Industrial Engineering and Management (IEM). Shamoon College of Engineering (SCE) is the largest engineering college in Israel with nearly 5,500 students, in six engineering departments, with approximately 550 students in the department of IEM. Both institutes' main campuses are located in the largest city of the southern part of Israel.

Both BGU and SCE have been using Britannica's LMS for close to a decade. The LMS was used, as in many other academic institutes, mainly for posting learning material, but also, in some cases, for conducting discussions, submission and grading of exercises, etc. (e.g. [8]). In the academic year 2015, both institutes switched to a different LMS - Moodle. Both institutes made no further changes in the technology or the supporting staff. No best practices known for IS implementation were followed (e.g. top management support and user involvement [9], effective program for user training [10], a lead user or a champion of the system promoting its use ([11]-[13]). For example, the change was not introduced or even referred to by the management of both institutions. In addition, the process was led by the IT staff and no rational or explanation for the change was offered to the users. Furthermore, users (instructors and students) were not involved in any stage of the implementation, training was offered in a single mail sent to the teaching staff, and only a handful registered and attended the technology-focused two hours training. This situation provided the authors with an exceptional opportunity to examine the impact of the platform change itself, with no other factors involved.

The remaining of the paper is organized as follows: Section II presents relevant literature, in Section III the research methodology is outlined, while Section IV depicts the results. The paper concludes with a discussion of the results in Section V.

\section{BACKGROUND}

Researches evaluating LMSs and blended learning environments use a variety of measures in their studies. Learning outcomes and the students' satisfaction are widely used (e.g. [14], [15]). However, as suggested by Garrison and 
Kanuka [16], technology offers great potential to enhance the educational process via blended learning. Indeed, many other aspects of learning have been examined in research. For example, students' perceptions of learning outcome (e.g. [17]), learning process (e.g. [18]) and learning experience (e.g. [19]), sense of community (e.g. [20]) and students' perceived benefits and use (e.g. [21]).

This study examines LMS from a perspective of IS success. IS success has been the focus of abundant of researches as IS requires massive investments and is expected to deliver added value to the implementing organization. DeLone and McLean [22], [23] assert that IS success may be measured in numerous ways, and classify them into six categories: (1) Information quality (accuracy of the information produced by the system, information availability, etc.); (2) System quality (e.g. system's response time and resource utilization); (3) Service quality (for example responsiveness, assurance of IS staff); (4) Intension to use (as reported by the users) and use (as reported by the user or according to the actual use based on system log files); (5) User satisfaction; and (6) Net benefit (by all spectrum of impacted entities, from individuals to economy in the national level). The model also indicates the interaction between these categories (see Fig. 1).

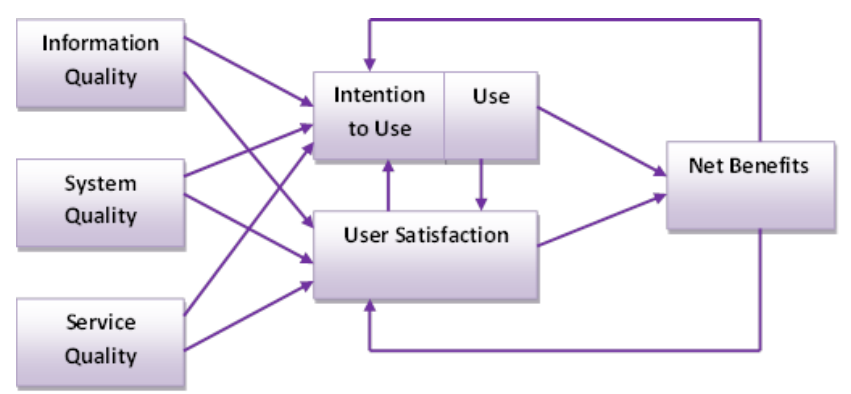

Fig 1. DeLone and McLean IS success model [22].

According to this model, information, system and service quality are determinants of user satisfaction. Au et al. [24] suggest that user satisfaction is a common and reliable measure for IS success. System quality is the focus of numerous researches and its effect on user satisfaction was examined in different settings. Sabherwal et al. [25] in a meta-analysis of 121 studies published between 1980 and 2004 found system quality to explain $31 \%$ of user satisfaction. The results remained consistent when contextual (e.g. top management support) and user related determinants (e.g. user experience) were considered.

System quality, in the context of LMS, may refer to ease of use, reliability, security and the design of the software according to the users use and needs [1], [26]. Several researches examine the effect of system quality on students' satisfaction from LMSs. For example, Klobas and McGill [1] examined the effect of students and instructors' involvement on students' use, satisfaction and benefit from the system, based on DeLone \& McLean [22] model. They found that the system quality has an effect on students' satisfaction. Islam [27] found environmental factors (access, ease of use, functionality, usability, reliability etc.) to impact students' satisfaction and dissatisfaction. Freeze et al. [26] examined system and information quality of an e-learning system impact on system use and satisfaction of students where the majority were enrolled to completely online courses. They found system and information quality to explain $83 \%$ of students' satisfaction. Roca et al. [28] examined the effect of system quality, service quality and information quality on confirmation and satisfaction based on the Technology Acceptance Model (TAM, [29]). They found system quality to explain $27 \%$ of variation in students' satisfaction. On the other hand, Lee and Lee [30] approximated system quality with perceived ease of use and found no significant correlation between perceived ease of use and satisfaction.

In all of these studies, examining system quality was based on students' reported feedback, a methodology which has its built in limitations. Furthermore, separating one of the three quality factors (i.e. system quality, information quality and service quality), from the others is rather complex. For example, the quality of the service may influence the users' perception of the system quality [1]. Indeed, prior to DeLone and McLean success model [23], many studies of end-user satisfaction did not explicitly separate information quality and system quality as antecedent of user-satisfaction [31].

In this research, however, the change in system quality is isolated from other possible factors influencing students' satisfaction by circumstances, simply because no other changes were made at the time of the platform replacement. Specifically, the information from the old LMS was migrated to the new system and the IS staff and its working procedures were unchanged. Therefore, information quality and service quality, the other determinants of user satisfaction (along with use) in DeLone and McLean's model [22], were not changed. This facilitates the attribution of all changes in user satisfaction to the change in system quality.

\section{METHOdOLOGY}

As detailed in the previous section, this study examines the effect of LMS platform replacement on students' satisfaction, i.e., the effect of system quality on user satisfaction, based on DeLone and McLean model [23] (see Fig. 2).

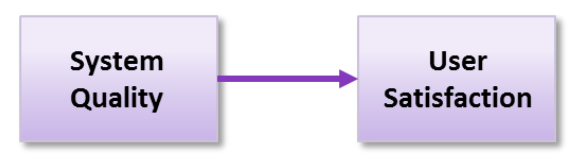

Fig. 2. Research model.

The explanatory variable in this research, LMS system quality, was treated as variable with only two values - the old system and the new system. The dependent variable, students' satisfaction, was measured via a questionnaire.

The instrument was composed of four statements regarding general satisfaction from the LMS (see Appendix). The students were asked to indicate their opinion on a 7 point Likert scale, ranging between strongly disagrees and strongly agrees. The items, based on previously validated tools [32], [33], were translated to the respondents' mother tongue (Hebrew) while consulting with three experts in the field of education and academic teaching.

The survey was distributed during a lecture, using a paper and a pencil, on the first week of two consecutive academic years -2015 and 2016. As the system was replaced at the beginning of 2015 academic year, the students were asked 
about the old LMS platform on the first week of that year, after two years of using that system and before they had a chance to use the new system. Then, at the beginning of the consecutive year (fall semester of 2016 academic year), after a year of use of the new system, the students were asked to express their opinion on the new LMS platform by filling out the same questionnaire. The survey was filled out by third year students from the departments of industrial engineering and management at BGU and SCE.

The collected data was analyzed in two phases. First, descriptive statistics of the collected data was calculated. Second, in order to evaluate the effect of the LMS change and the academic institute on students' satisfaction, a regression analysis was performed.

\section{RESUlts}

The total number of respondents was 240 . The majority of the respondents was from BGU $(75.4 \%)$ and the minority from SCE $(24.6 \%)$, due to the difference in the number of students in the two institutions. The Cronbach's $\alpha$ score for the four satisfaction statements was 0.963 , which indicates the reliability of the questionnaire. The satisfaction for each respondent was calculated as the average of the four satisfaction statements. Table I presents descriptive statistics of the collected data.

TABLE I: DESCRIPTIVE STATISTICS

\begin{tabular}{lllll}
\hline \hline & & Frequency & Percent & $\begin{array}{l}\text { Satisfaction } \\
\text { Average }\end{array}$ \\
\hline System Quality & Old LMS & 130 & $54.2 \%$ & 5.483 \\
& New LMS & 110 & $45.8 \%$ & 4.777 \\
Institution & BGU & 181 & $75.4 \%$ & 5.189 \\
& SCE & 59 & $24.6 \%$ & 5.068 \\
Overall & & 240 & $100.0 \%$ & 5.159 \\
\hline \hline
\end{tabular}

TABLE II: REGRESSIONS FOR USER SATISFACTION

\begin{tabular}{|c|c|c|c|c|c|c|c|c|}
\hline & & coefficient & $t$-statistic & $p$-value & 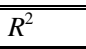 & $\overline{\operatorname{Adj} R^{2}}$ & $F$-statistic & $p$-value \\
\hline \multirow[t]{3}{*}{ Model 1} & System Quality & -0.711 & -4.4 & $<0.001$ & & & & \\
\hline & Institution & -0.154 & -0.824 & 0.411 & & & & \\
\hline & Model summary & & & & 0.077 & 0.069 & 9.893 & $<0.001$ \\
\hline \multirow[t]{2}{*}{ Model 2} & System Quality & -0.705 & -4.374 & $<0.001$ & & & & \\
\hline & Model summary & & & & 0.074 & 0.071 & 19.133 & $<0.001$ \\
\hline
\end{tabular}

Responses collected for the old and new system were divided close to even $(54.2 \%$ for the old LMS while $45.8 \%$ for the new system). Likewise, the gender of the respondents was divided close to equal ( $47 \%$ males and $53 \%$ females). The overall average satisfaction was 5.159 and its standard deviation was 1.291 .

Regression analysis found that the user's satisfaction was affected by the change of system (p-value<0.001) but not effect by the institution, i.e. BGU and SCE (p-value=0.411). After removing the institution variable from the equation, the model explains 7 percent of the satisfaction's variance (see Table II). The satisfaction from the new system was lower (average 4.78) compared to the satisfaction with the old LMS system (average 5.48).

\section{DISCUSSION}

This research examined the impact of platform change, i.e., system quality of LMS, on students' satisfaction from the system in two academic institutes. The special circumstances enabled the examination of the effect of the system quality on students' satisfaction with no other factors that may influence it, present (for example, no organizational processes or activities were made). Furthermore, no implementation activity was made to support this change (for example, there was no training program or change process management). The data analysis indicates that only a relatively small portion (7\%) of the shift in students' satisfaction originated from system quality. The change in satisfaction from the system was not significantly different between the academic institutes, in spite of differences in size and population.

These results may indicate that LMSs have reached maturity in both design and functionality, and therefore, one platform does not offer significant advantage over another. The evidence of significant change in students' satisfaction which could not be attributed to the system itself may suggest that if organizational processes known to support IS implementation will be followed, user satisfaction may increase. Such organizational processes might include user involvement in early stages of the implementation, management involvement, training programs, champion users, etc.

In this study, the system features, design and other factors that may have shaped students satisfaction were not examined and the systems quality was treated as a dichotomous variable (old and new LMS). It is possible that attributes such as perceived affordances and usability has shaped students perception of the system and even instructors' activity as suggested by Rubin et al. 2013 [34]. Therefore, further exploration of instructors' use of the system and students' satisfaction from it (e.g. via interviews) may shed more light on the reasons for students' lower satisfaction from the new LMS. Such examination might also offer practical recommendations for higher education administrators concerning steps to be made in order to increase students' satisfaction from one of the most intensively used information systems in their academic life.

Furthermore, revisiting students' satisfaction from the new LMS in a few years, when the new system will no longer be new, might facilitate the understanding of the effect of habit 
on the satisfaction from LMSs.

\section{APPENDIX: SURVEY INSTRUMENT}

1) Overall, the system is successful

2) Overall, I am satisfied with the system

3) Overall, the system has met my expectations

4) Overall, I am satisfied with the use been made with the system

\section{REFERENCES}

[1] J. E. Klobas and T. J. McGill, "The role of involvement in learning management system success," Journal of Computing in Higher Education, vol. 22, pp. 114-134, 2010.

[2] T. Soffer, R. Nachmias, and J. Ram, "Diffusion of web supported instruction in higher education - The case of Tel-Aviv University," Journal of Educational Technology \& Society, vol. 13, pp. 212-223, 2010.

[3] L. Macchiusi and S. Trinidad. "Information and communication technologies: The adoption by an Australian University," in Proc. Teaching and Learning Forum, 2016.

[4] J. Bennett and L. Bennett, "A review of factors that influence the diffusion of innovation when structuring a faculty training program,' The Internet and Higher Education, vol. 6, pp. 53-63, 2003.

[5] C. J. Bonk and C. R. Graham, The Handbook of Blended Learning: Global Perspectives, Local Designs, John Wiley \& Sons, San Francisco, 2012, ch. 27, pp. 374-386.

[6] G. Naveh, D. Tubin, and N. Pliskin, "Web sites for every department course," Campus-Wide Information Systems, vol. 23, pp. 68-75, 2006.

[7] R. Nachmias and J. Ram, "Research insights from a decade of campus-wide implementation of web-supported academic instruction at Tel Aviv University," The International Review of Research in Open and Distributed Learning, vol. 10, 2009.

[8] G. Naveh, D. Tubin and N. Pliskin, "Student LMS use and satisfaction in academic institutions: The organizational perspective," The Internet and Higher Education, vol. 13, pp. 127-133, 2010.

[9] M. Aziz and H. Salleh, "People critical success factors of IT/IS implementation: Malaysian perspectives," World Academy of Science, Engineering and Technology, International Journal of Social, Behavioral, Educational, Economic and Management Engineering, vol. 5, pp. 928-935, 2011

[10] T. K. Bikson., B. A. Gutek, and D. A. Mankin, "Implementing computerized procedures in office settings, the rand corporation," Santa Monica, CA, 1987

[11] T. H. Kwon and R. W. Zmud, "Unifying the fragmented models of information systems implementation," Critical Issues in Information Systems Research, 1987.

[12] R. L. Purvis, V. Sambamurthy, and R. W. Zmud, "The assimilation of knowledge platforms in organizations: An empirical investigation,' Organization Science, vol. 12, pp. 117-135, 2001

[13] C. A. Beatty. "Implementing advanced manufacturing technologies: Rules of the road," Sloan Management Review, vol. 33, pp 49-60, 1992.

[14] P. Ginns and R. Ellis, "Quality in blended learning: Exploring the relationships between on-line and face-to-face teaching and learning," The Internet and Higher Education, vol. 10, pp. 53-64, 2007.

[15] J. H. Wu, R. D. Tennyson, and T. L. Hsia, "A study of student satisfaction in a blended e-learning system environment," Computers \& Education, vol. 55, pp. 155-164, 2010.

[16] D. R. Garrison and H. Kanuka, "Blended learning: Uncovering its transformative potential in higher education," The Internet and Higher Education, vol. 7, pp. 95-105, 2004.

[17] M. V. López-Pérez, M. C. Pérez-López, and L. Rodríguez-Ariza, "Blended learning in higher education: Students' perceptions and their relation to outcomes," Computers \& Education, vol. 56, pp. 818-826, 2011.

[18] M. A. Andresen, "Asynchronous discussion forums: Success factors, outcomes, assessments, and limitations," Educational Technology and Society, vol. 12, pp. 249-257, 2009.
[19] A. Buket and M. Yilmaz-Soylu, "A study of student's perceptions in a blended learning environment based on different learning styles," Educational Technology \& Society, vol. 11, pp. 183-193, 2008.

[20] A. P. Rovai and J. Hope, "Blended learning and sense of community: A comparative analysis with traditional and fully online graduate courses," The International Review of Research in Open and Distributed Learning, vol. 5, 2004.

[21] S. Lonn and S. D. Teasley, "Saving time or innovating practice: Investigating perceptions and uses of Learning Management Systems," Computers \& Education, vol. 53, pp. 686-694, 2009.

[22] W. H. DeLone and E. R. McLean, "The DeLone and McLean model of information systems success: A ten-year update," Journal of Management Information Systems, vol. 19, pp. 9-30, 2003.

[23] W. H. DeLone and E. R. McLean, "Information systems success: The quest for the dependent variable," Information Systems Research, vol. 3, pp. 60-95, 1992.

[24] N. Au, E. W. T. Ngai, and T. C. E: Cheng, "A critical review of end-user information system satisfaction research and a new research framework," Omega, vol. 30, pp. 451-478, 2002.

[25] R. Sabherwal, A. Jeyaraj, and C. Chowa, "Information system success: Individual and organizational determinants," Management Science, vol. 52, pp. 1849-1864, 2006

[26] R. D. Freeze, K. A. Alshare, P. L. Lane, and H. J. Wen, "Is success model in e-learning context based on students' perceptions," Journal of Information Systems Education, vol. 21 pp. 173-184, 2010.

[27] A. N. Islam, "Sources of satisfaction and dissatisfaction with a learning management system in post-adoption stage: A critical incident technique approach," Computers in Human Behavior, vol. 30, pp 249-261, 2014.

[28] J. C. Roca, C. M. Chiu, and F. J. Martínez, "Understanding e-learning continuance intention: An extension of the technology acceptance model," International Journal of Human-Computer Studies, vol. 64, pp. 683-696, 2006.

[29] F. D. Davis, "Perceived usefulness, perceived ease of use, and user acceptance of information technology," MIS Quarterly, vol. 13, pp. 319-340, 1989.

[30] J. K. Lee and W. K. Lee, "The relationship of e-learner's self-regulatory efficacy and perception of e-learning environmental quality," Computers in Human Behavior, vol. 24, pp. 32-47, 2008.

[31] McKinney, K. Yoon, and F. M. Zahedi, "The measurement of web-customer satisfaction: An expectation and disconfirmation approach," Information Systems Research, vol. 13, pp. 296-315, 2002.

[32] P. C. Palvia, "A model and instrument for measuring small business user satisfaction with information technology," Information \& Management, vol. 31, pp. 151-163, 1996.

[33] N. Hisham, P. Campton, and F. FitzGerald, "A tale of two cities: A study on the satisfaction of asynchronous e-learning systems in two Australian universities," in Proc. Ascilite 2004 on Beyond the Comfort Zone, pp. 395-402, 2004

[34] B. Rubin, R. Fernandes and M. D. Avgerinou, "The effects of technology on the community of inquiry and satisfaction with online courses," The Internet and Higher Education, vol. 17, pp. 48-57, 2013.

Gali Naveh holds a B.Sc. in computer science and the M.Sc. and Ph.D. in information systems from Ben Gurion University of the Negev, Beer Sheva, Israel, on 2009. She is a lecturer in the Department of Industrial Engineering and Management at Shamoon College of Engineering, Israel. Dr. Naveh has rich practical experience with post-secondary educational institutes and information systems implementation in business organizations. Her main interest is information and communication technologies integration processes and their value in academic and industrial settings.

Amit Shelef completed her Ph.D in industrial engineering and management, Ben Gurion University of the Negev, Beer Sheva, Israel, 2014. She is a lecturer in the Department of Industrial Engineering and Management at Shamoon College of Engineering, Israel. Dr. Shelef specializes in statistical analysis of time series data and implementation of the Gini's Mean Difference (GMD) as a measure of spread instead of the variance. 